\title{
How Serious Regional Economic Inequality in Jordan? Evidence from Two National Household Surveys
}

\author{
Mohammed Issa Shahateet \\ Princess Sumaya University of Technology, P.O. Box 1438, Al-Jubaiha, Amman 11941, Jordan
}

\begin{abstract}
The objective of this study is to measure and explain the extent of regional economic inequalities in Jordan. To do so, this study uses the raw data of two national household surveys on expenditure and income that covers 5,971 and 11,153 households in 1997 and 2002, respectively. As a check on the empirical results, the study applies four measures of inequality: The Gini index, Atkinson's index, the 90/10 ratios, and the standard deviation of the natural logarithm. The study concludes that economic inequality has increased over the five years of growth period following 1997. The overall increase is estimated at about $17 \%$ indicating a shift in the function of income distribution so that income may have become more unequal. In its evaluation of income distribution, the study has reached the conclusion that regional economic inequality in Jordan is serious and there is a need for a more space-balanced approach.
\end{abstract}

Keywords: Gini index, Atkinson's index, income distribution, regional economic inequality

\section{INTRODUCTION}

In economic literature, there has been an increasing interest in studying income distribution to justify or evaluate economic performance and policies. To understand what life is like in a country, it is not enough to know its per capita income or the percentage of poor people, because quality of life in a country also depends on how income is distributed. Macroeconomic studies that addressed economic inequality or income distribution in Jordan are few ${ }^{[1-3]}$. These studies focused on measures of the overall economic inequality in Jordan and neglected regional economic inequality and factors affecting income distribution. More recent research on Jordanian data has developed ways to identify the most important determinants of income inequality. Kharabsheh ${ }^{[4]}$ found that demographic and socio-economic factors represented by household size, urban ratio, annual per capita income, and economic dependency rate were the main determinants that, positively, affect the income inequality in Jordan with disproportion of the size of effect. Shaban et al. ${ }^{[5]}$ showed that the overall economic inequality in Jordan in 1997 was roughly typical for Arab countries, with Tunisia, Morocco, and Yemen showing greater inequality than that of Jordan. However, Algeria and Egypt had less inequality levels. Worldwide, India and Poland had lower levels while most Latin American countries had much greater inequalities than those prevailed in Arab countries.

This study examines the extent of economic inequality from regional and historical perspectives in 1997 and 2002. The analysis of variance was carried out using real per capita household income data, to see whether, or not, there were variations in income levels that could be attributed to place of residence in both 1997 and 2002. After finding that these variations existed, four measures of inequality were calculated to measure the seriousness of income inequality. In doing so, this study aims at making five contributions: First, providing statistical evidence that there were serious differences among well-being of the governorates of Jordan that could be due to an economically unjustified concentration of growth in some parts of Jordan at the expense of other regions. Second, measuring inequalities, within each governorate and in Jordan as a whole, that will help clearing the picture of income distribution. Third, providing evidence that inequality has increased between 1997 and 2002 in Jordan and in most of its governorates. Fourth, this study contributes to income-inequality literature by using income for a developing country -Jordan, to provide evidence that income inequality is a bad form of development. Finally, the fifth contribution is related to policy debates concerning the success and failure of economic programmes in reducing regional inequalities.

\section{MATERIALS AND METHODS}

This study reviews relevant existing studies on economic inequality including those related to Jordan and examines the raw data provided by the Household Income and Expenditure Survey (HIES) of 1997 and the HIES of 2002/2003. After that it tests if economic inequality existed among the (twelve) governorates of Jordan in both 1997 and 2002. Then it sheds light on the degree of seriousness of economic inequality and provides evidence on the direction of its changes.

Corresponding Author: $\quad$ Mohammed Issa Shahateet, Princess Sumaya University of Technology, P.O. Box 1438, Al-Jubaiha, Amman 11941, Jordan 
In addressing regional economic inequalities in Jordan, this study assumes that income is a direct measure of individual, and household, well-being. The nominal values of income are adjusted for changes in prices over time using the consumer price index. To compute real per capita income, gross current income is divided by the number of household members. The assertion that economic inequality is declining through comparing the averages of per capita income among governorates tells little about whether the quality of life of the poor is improving or getting worse. In order to decide whether economic inequality has increased or decreased it is essential to apply statistical tests and other measures of economic inequality. In principle, there are more factors that should be considered to decide whether economic inequality has increased or decreased. These include, among others, the difference in sample sizes, the standard error, household size, prices, and the change in wage levels or earnings over the two reference periods under study.

As a first step, the study applies the analysis of variance (ANOVA) to test a list of hypothesis of no economic inequality among the (twelve) governorates of Jordan. The results of these tests indicate that regional economic inequality existed in both 1997 and 2002. The second step involves identifying where these inequalities occurred. In the third step the study measures the degree of seriousness of this economic inequality. For this purpose, the study uses the most recent and common inequality measures. These include: The Gini index, the Atkinson's inequality index, the 90th -10 th percentile ratio, and the standard deviation of the natural logarithm of real per capita income. Our measures of inequality were calculated using all observations (ungrouped data). Most studies, however, that do not have access to raw data calculate such measures from grouped data, which are usually found in the form of a table published by official departments of statistics. Any measure of income inequality that is based on grouped data is sensitive to the number of classes chosen and the assignment of class intervals and will suffer from grouping error. Grouping income data into classes also results in a loss of information. Studies that have access to the relevant household level data are accurate computational methods for estimating inequality measures directly from the data. Because households vary in size, a distribution in which households are ranked according to per capita household income, rather than according to total household income is superior for many purposes since the distribution of household income may overstate the income inequality.

Sample of the study: Empirical results and conclusions of this study are based on the raw data of the Household Income and Expenditure Survey (HIES) of 1997 and the raw data of Questionnaire Number 1 (The General Questionnaire) of the HIES of 2002 that were conducted by Jordan's Department of Statistics. The HIES of 1997 covered 6,000 households while the HIES of 2002 surveyed a larger sample of 12,792 households using two-stage stratified cluster sampling technique designed to give reliable estimates of consumption and income at the sub-district level. Most of the common questions between the two surveys were considered comparable for the purposes of calculation of income aggregate, despite the time span between the two surveys that might produced more reliable results for 2002 than those of 1997. Our sample is composed of all households who reported positive income producing a final data set that consisted of 5,971 and 11,153 households for 1997 and 2002, respectively.

Real per capita income figures are used in this research as a welfare measure. However, wealth is a better indicator than is income but measurement problems are daunting enough to make such figures even less reliable than that of income data.

The quality of data raised three issues. The first is related to the degree of accuracy of income data collected by the Department of Statistics through a sample survey. Obviously, it would be naïve to regard all income data as being free of errors in absolute sense. Rather, they are constructs, worth knowing, and of special value when they are tracked over time or compared across regions. Given the large number of households, the distribution of these households, and the sampling methodology, one can safely assume that the two surveys were representative socioeconomic surveys of the living standards of households in all governorates of Jordan. The second issue is concerned with the inclusion or exclusion of some income items. For this issue, and in order to control for any bias we took into account gross current income that includes all (seven) income items which are important in determining the level of welfare of a household. It is important to remember how the welfare indicators (variable i520 in 1997 data and variable C939 in 2002 data) were derived. For testing and data analysis, gross current income was used for both 1997 and 2002 data. This gross current income includes 7 income subgroups. The third issue is related to regional comparisons prior to 1997. Since the classification of governorates during this period was different from that of 1997 and 2002, it was not possible to make these comparisons for the period prior to 1997.

Inequality in economic theory: Many theories have been constructed to assess the macroeconomic relations between inequality and economic growth. More specifically, the question whether a conflict exists between economic growth and income distribution has been widely analysed in the literature over the past several decades. This question is particularly acute in the case of growth of developing countries, where such growth is generally accompanied by a changing structure of economic activity: a transition from 
agriculture to industrial and service activities. Many researchers have shown the potential of increasing economic inequality as a consequence of economic growth. They argued that macroeconomic growth does not necessarily contribute to the diminution of economic inequality and may even increase it, consequently constraining the prospects for growth in the longer run. As real incomes rise during a period of high economic growth, there is a danger that the gap between the well-off and the poor can grow. This can happen even while the income of the poor increases in real terms.

Applied research conducted in most developed countries provided evidence of the effect of past history of growth on household income (or consumption) at the micro level. This has been demonstrated by analysing data for Australia ${ }^{[6-9]}$, Canada ${ }^{[10,11]}$, Europe ${ }^{[12]}$, Italy $^{[13,14]}$, the United Kingdom ${ }^{[15,16]}$ and the United States ${ }^{[17-19]}$. Empirical results of these studies indicated that macroeconomic growth does not necessarily lead to the reduction of more equal distribution of income.

Analyses based on a simplistic understanding of the Harrod-Domar model of economic growth had argued that unequal distribution of income should promote economic growth because rich people save more than poor people. Thus, income inequality was regarded as good for development because it would contribute to more savings, investment, and growth. However, this claim was not empirically supported by evidence. In fact, there is enough evidence that relative income inequality is a necessary drag on economic growth, at least in developing countries. Barro ${ }^{[20]}$ provided evidence that economic inequality reduces growth in poor countries and helps growth in rich ones.

Those who supported the claim that equality helps to promote economic growth and vise versa built most of their argument on the success of the East Asian countries, especially Japan, Hong Kong, Singapore, South Korea, and Taiwan. There is no doubt that the growth of the economies of these countries is a success story as was their more equal distribution of income.

Persistence of economic inequality: The persistence of economic inequality is also a matter of debate. Some studies argue that, generally speaking, the poor will always remain poor and the rich will always remain rich and, therefore, economic inequality persists. The chances of the poor is becoming rich are negligible. This can only happen when luck intervenes in the life of the poor. For this reason, a number of economists and political theorists who neglect the importance of equality denied that there exists, either in nature or in social organisations, any basis for the claim that human beings should have equal income and wealth. They argued that if the state seeks to make people equal in one regard such as incomes they will still be unequal in others such as educational qualifications or wealth holdings and that the attempt to achieve it could interfere with people's basic freedom. For some economists, equality of income is impossible and undesirable, given the different abilities with which each person is born.

It is true that equality is inherently contradictory and people had never been equal, in mathematical sense, but the aim of reducing economic inequality is justified on economic and moral basis. This can be explained not only through inherited lack of wealth but also through distorting effects of economic and social policies on the economy and on the state's ability to allocate resources efficiently. It can also be explained by the move away from socioeconomic equality as an objective of economic policies. The objective of decreasing economic inequality is built on the basis of reducing differentials to a size that is not destructive of social equality rather than on the basis of attempting to reduce them to zero. The focus of economic programmes, therefore, is not to set a target of perfect equality, but rather to aim at smoothing economic inequality to what can be called minimum acceptable inequality or, simply, "acceptable inequality". Of course, no one seriously advocates, as an ideal, perfect equality of income, first because such extreme equality would be unenforceable under any known economic system, and secondly, because it is believed that persons with skills would not use their abilities fully enough unless there were differences between their pay and that of unskilled workers.

Causes of inequality: The causes of income inequality are open to broad debate. Several factors have been blamed for this inequality including economic structure or system (such as capitalism, socialism or communism), ongoing or past wars, and individuals' different abilities to create wealth. This suggests that socioeconomic policies, including economic adjustment programmes, alone cannot fully explain the changes in income inequality, but the matter is actually much more complicated, yielding no easy or general answers.

Explaining the determinants (or causes) of economic inequality is beyond the scope of this study. However, economic theories that dealt with this issue considered economic inequality as output. These include factor share and market imperfections theories especially information asymmetries, efficiency wages and selection models.

Milanovic ${ }^{[21]}$ finds that tariff reduction is associated with a rise in inter-industry wage inequality. Behrman et al. ${ }^{[22]}$ did not find a significant impact of liberal trade regimes on wage differentials in Latin America, but financial liberalisation and high technology exports in the context of a liberal trade regime did contribute to a rise in wage inequality. Globalisation and competition from imports of cheap unskilled labour-intensive products from poorer countries especially imports of clothing, textiles and apparel may, in recent years, aggravated economic inequality. Differences in income 
can also be related directly to differences in work. For the most part, upper-income families in the US do better than lower-income families because they work more.

Economic inequality is often brought about more by domestic profligacy in matters of subsidies to the rich, salaries for the bloated public sector, and military extravaganza. Bardhan ${ }^{[23]}$ argued that when governments are faced with mounting fiscal deficits they often find it politically easier to cut the public expenditures for the voiceless poor and that is primarily due to the domestic political clout of the rich who are disinclined to share in the necessary fiscal austerity. He adds that "it is always convenient to blame an external agency for a problem that is essentially domestic in origin".

Among other factors that impact economic inequality are discrimination (racial, gender, religious, and caste), heritage such as innate ability, cultural differences, and educational achievements. Recent research also suggests that the degree of income inequality in society may be related to the health status of a population. Another line of research did not find systematic relationship between changes in trade volumes and changes in household income inequality. The increase in growth rates that accompanies expanded trade therefore on average translates into proportionate increases in income of the poor.

"For it goes without saying that in a free economy, some people will always earn much more money than others, and a given person will, during some stages of his life, earn much more than in other stages. It is therefore far from clear that there is such a thing as a "right" distribution of income, and to our knowledge, no critic of current patterns of income distribution has set forth any meaningful criteria by which the "right" income distribution can be determined. Instead of articulating such criteria, critics have generally been content to argue that income inequality is "increasing" or "widening" and have assumed that it goes without saying that such a trend, if true, would be bad. Both the belief that income inequality is increasing, and the assumption that any such increase must necessarily be bad, need to be critically examined".

Effects of economic inequality: The issue of income distribution and the gap between the income of the highest and the lowest income earners affect economic growth, human development, poverty, conflict, social cohesion, democracy, to name but a few. An excessively equal income distribution can be bad for economic efficiency. Low inequality may deprive people of the incentives needed for their active participation in diligent work and vigorous entrepreneurship needed for economic growth.

On the other hand, excessive inequality adversely affects people's quality of life, leading to higher incidence of poverty and so impeding progress in employment, health, education and contributing to crime. High inequality threatens political stability which increases the risks of investment. It also limits the use of important market instruments such as changes in prices and fines and may discourage certain basic norms of behaviour among economic agents. These are among the reasons some international experts recommend decreasing income inequality in developing countries to help accelerate economic and human development. If income differences are very large, this will almost inevitably create a segregated society in which people live very different styles of life and associate socially almost entirely with those on similar incomes.

But why economic inequality reduction should be in the heart of economic policy? Or does it matter, to economic growth, whether the gap between poor and rich should be narrowed? It matters firstly because an increase in economic inequality may undermine the ability of the poor to function as equals in society. It matters secondly because widening the gap is likely to prevent the poor from participating in economic activities hence loosing a segment of the labour force that may increase the nation's production of goods and services. It matters thirdly because the evidence points to the fact that the most sustainable way to reduce economic inequality is not part of economic policies. Greater equality is not perhaps a sufficient objective of economic policies but it is a necessary one that justifies economic reforms or adjustment programmes. It matters fourthly because the reduction of inequalities of income will help in transferring resources to those in need. More importantly, a decrease in income inequalities is likely to reduce inequalities of opportunities which arise from inherited social and economic differences. It matters fifthly because many discussions of economic policies are dominated by the unfortunate tendency to correlate economic performance with poverty reduction without any consideration for inequality.

Perhaps the worst thing about economic inequality is the problems, constraints and insults associated with it. These are of concern not just within a single generation, but even more, from generation to generation. It creates a loss not only for the persons who are so constrained by economic, social, cultural or political circumstances, but also for the whole society. Some economists believe that this loss may be even greater than that for the poor. Economic inequality may negatively affect social capital, which could contribute to crime or even revolution. Indeed, Karl Marx based much of his critique of capitalism on economic inequality between providers of capital and providers of labour. Alesina et al. $^{[24]}$ find that inequality negatively affects happiness in Europe.

Until the issues of economic inequality for the poor in developing countries are satisfactorily resolved, inequality is bound to raise anxiety and hostility. 
Another practical argument in favour of economic inequality reduction is the idea that economic inequality reduces social cohesion and increases social unrest, thereby weakening the society. This is true especially when we know that economic inequality invariably translates to political inequality, which further aggravates the problem. There is also a concrete evidence that inequality of wealth and income motivates the poor to engage in crime, riots, and other disruptive activities. Analysing a panel data for 86 countries, Barro ${ }^{[20]}$ provided empirical evidence that the negative effect of economic inequality on growth shows up for poor countries, but that the relationship for rich countries is positive. However, the overall effect of economic inequality on growth is weak.

Test of variations: The study postulates that there are no significant variations in real per capita income among governorates. In other words, the test seeks to determine whether, or not, there are differences in economic well-being that could be attributed to areas of residence (governorates). This problem looks upon real per capita income $I_{i j}$ as values assumed by independent random variables having normal distributions with the means $\mu_{i}$ and the variance $\sigma^{2}$. Hence, the assumed model can be written as $I_{i j}-\mu_{i}=\alpha_{i}+u_{i j}$ for $i=1,2, \ldots$, 12 and $j=1,2, \ldots, n_{i}$

The null hypothesis we shall want to test can, symbolically, be stated as:

$H_{0}: \alpha_{1}=\alpha_{2}==\alpha_{12}=0$ Vs. $H_{1}: \alpha_{i} \neq 0$ for at least one value of $i=1,2, \ldots, 12$.

Where

$i=1,2, \ldots, 12$ is an index for governorates;

$j=1,2, \ldots, n_{i}$ is an index for the number of income observations;

$n_{i}=$ number of income observations in governorate $i$;

$I_{i j}=j$ th real per capita income in governorate $i$;

$\mu_{I}=$ The arithmetic mean of real per capita income in governorate $i$;

$\alpha_{i}=$ The effects of the $i$ th governorate;

$u_{i j}=$ Error terms which are assumed to have mean zero and constant variance.

Since this test will give different results when applied to households instead of individuals, the test is carried out for both real per capita household income and real household income.

Measures of income inequality: In economic literature, there are several measures of inequality that are based on theories of statistical distributions. This study applies the most common measures: The Gini index, the Atkinson's inequality index, the 90/10 ratio and the standard deviation of the natural logarithm. Most of these measures are calculated from grouped data. However, the problem of losing information is likely to occur when record units are grouped into classes that might have different heights according to arbitrary selection of class height.

The Gini index: The coefficient is a measure of inequality developed by the Italian statistician Corrado Gini and published in his 1912 paper "Variabilità e mutabilità" ${ }^{[25]}$. It has widely been used as a measure of income inequality, but can be used to measure any form of uneven distribution. The Gini coefficient is a number between 0 and 1 , where 0 corresponds with perfect equality and 1 corresponds with perfect inequality. The Gini coefficient is used to show the degree of economic inequality, as expressed by income data, between different geographical regions. It can also be used to show how economic inequality has been changing over a period of time. It is most easily calculated from unordered size data as the relative mean difference. Formally, the Gini coefficient is given by:

$$
G=\frac{\sum_{i=1}^{n} \sum_{j=1}^{n}\left|X_{i}-X_{j}\right|}{2 n^{2} \mu}
$$

Where $G$ is the Gini coefficient, $n$ is the number of data observations, $X_{i}$ is the $i$ th income, $X_{j}$ is the $j$ th income and $\mu$ is the mean of all income observations. The main advantage of the Gini coefficient is that it is a measure of relative inequality which is not a measure of average income or some other variable which is unrepresentative of most of the population, such as gross domestic product. It has a close relation to Lorenz curve and can be easily calculated from normally available data. It also satisfies four important principles: anonymity, scale independence, population independence, and transfer principle. In reality, neither perfect inequality nor perfect equality is possible. For this, the Gini index (which is the Gini coefficient times 100 ) is always greater than 0 and less than 100. The Gini index also has the advantage of assessing differences between geographical regions, and over time, in specific and reasonably comparable terms.

Atkinson's index: The Atkinson's index is one of the few inequality measures that explicitly incorporate normative judgments about social welfare. The index is derived by calculating the so-called equity-sensitive average income which is defined as that level of per capita income to the total welfare generated by the actual income distribution. The Atkinson's index is calculated according to the formula

$$
A=1-\left[\frac{1}{n} \sum_{i=1}^{n}\left(\frac{Y_{i}}{\bar{Y}}\right)^{1-\varepsilon}\right]^{1 /(1-\varepsilon)}
$$

where $A$ is the Atkinson's inequality index, $n$ is the number of income observations (or intervals), $Y_{i}$ is the $i$ th value of income (or mean income of interval $i$ ), $\bar{Y}$ is the mean income of the entire distribution, and $\varepsilon$ is a measure of the degree of inequality aversion. The 
parameter $\varepsilon$ reflects the strength of society's preference for equality, and can take values ranging from zero to infinity. When $\varepsilon>0$, there is a social preference for equality (or an aversion to inequality). As $\varepsilon$ rises, society attaches more weight to income transfers at the lower end of the distribution and less weight to transfers at the top.

The advantage of the Atkinson's index is that it is readily decomposable by population subgroup. Being a relative index, the Atkinson's index is a normative and homothetic in income and hence scale free. Like the Gini coefficient, the Atkinson's index satisfies the Lorenz dominance criterion. Also, both indices have well-known asymptotic properties for the computation of standard errors and confidence bounds.

The 90/10 ratio: The 90/10 ratio is the ratio between real per capita income of the household at the $90^{\text {th }}$ percentile and the real per capita income of the household at the $10^{\text {th }}$ percentile of the distribution. This measure could be looked at as a ratio of two location measures that do not make use of all observations. The $10^{\text {th }}$ percentile value, for example, is not affected by other percentiles. In other words, other percentiles may increase or decrease without affecting the value of this measure. The importance of this measure stems from its use by the World Bank in comparing the gap between rich and poor in each country or between groups of countries. However, this measure has a shortcoming in that it does not make use of all the values of income observations. As a result, the values of this ratio should be interpreted with caution. Since thresholds of grouped data are subject to change according to the length (or height) of class, our inequality measures were not affected by these changes. For this purpose our statistic is not sensitive to the changes in coding thresholds.

Standard deviation of the natural logarithm: Unlike the 90/10 ratio, this measure makes use of all income observations. Like the previous measures, it could be calculated for grouped and ungrouped data. In this study, natural logarithm of real per capita household income is calculated then the standard deviation of the resultant values is computed.

\section{RESULTS AND DISCUSSION}

Empirical analysis produced interesting results towards economic inequality levels, especially when several levels of economic inequality across geographical regions are considered. Using data from two national household surveys, the study finds that there were significant variations in income among the governorates of Jordan in 1997 and 2002. It also provides empirical evidence that there was a rising income inequality over the period 1997-2002. As shown below, the quantitative results are robust to different measures of inequality. A picture that is almost identical to all four measures indicating that there were significant increases in economic inequality in most of the governorates of Jordan.

Differences between governorates: The results of ANOVAs concerning real per capita income, for both 1997 and 2002, are summarised in Table 1. As can be seen, the obtained value of the test statistic $F$, the value calculated from the samples, exceeds the critical value. Getting $F_{c}=12.445$ and 15.898 for 1997 and 2002, respectively far beyond their critical value, $F_{t}=1.79$, implies that there were statistically significant differences between real per capita incomes that could be attributed to area of residence. Consequently, the idea that the null hypothesis is true can be rejected. In other words, there were significant differences in real per capita income that could be attributed to governorates. This is true not only at the 5\% level of significance but also at a much less than 0.001 level of significance. Comparing ANOVA results for 1997 and 2002, we find a persistent and even growing unequal distribution of real per capita income in spite of the relatively rapid macroeconomic growth. One important feature of the empirical findings is the variations in between-governorates real per capita income inequality. Empirical results of the assumed model also imply that there were increases in between-governorates income inequalities due to real differences between economic well-being of the governorates of Jordan.

Summarising the results of this analysis, the study finds that the macroeconomic growth of Jordan's economy since 1997 did not contribute significantly to the reduction of economic inequality. Most importantly, inequalities mainly result from income gaps between the twelve governorates.

Empirical results of the Gini indices: As shown in Table 2, the Gini index has increased from 33.9 to 39.6, an increase of about 17 per cent. Since the Gini index considers each governorate as a separate entity, the increase in the Gini index for Amman governorate from about 36.8 to 44.0 should be interpreted as an increase of about $20 \%$ in differences among per capita incomes between 1997 and 2002. Noticeable changes in increased inequality were made in Tafeelah, Karak, and Jerash governorates. This does not imply that these governorates became richer or poorer; rather the distribution of income became more unequal. On the other hand, Ma'an, Madaba, and Zarka governorates had lesser changes in income than other governorates. It can be noticed that, generally speaking, traditionally poor governorates such as Zarka, Madaba, Mafraq, and, to some extent, the governorates of the South had less inequality. This does not suggest that Jordan has reduced inequality in these governorates but the increase in inequality was less in comparison to other governorates. It should be mentioned that some differences may be due to a better methodology of data collection in 2002 than that of 1997. 
Am. J. Appl. Sci., 3 (2): 1735-1744, 2006

Table 1: Summary of ANOVA results of real per capita income, 1997 and 2002

\begin{tabular}{|c|c|c|c|c|c|}
\hline Source of variation & Sum of Squares & df & Mean Square & $F$ & $\mathrm{Sig}$ \\
\hline Between governorates & $131,065,968$ & 11 & $11,915,088$ & 12.445 & .000 \\
\hline Within governorates & $5,705,239,902$ & 5,959 & 957,416 & & \\
\hline Total & $5,836,305,870$ & 5,970 & & & \\
\hline \multicolumn{6}{|l|}{2002} \\
\hline Source of variation & Sum of Squares & df & Mean Square & $\mathrm{F}$ & Sig. \\
\hline Between governorates & $274,923,506$ & 11 & $24,993,046$ & 15.898 & .000 \\
\hline Within governorates & $17,514,448,400$ & 11,141 & $1,572,071$ & & \\
\hline Total & $17,789,371,907$ & 11,152 & & & \\
\hline
\end{tabular}

Note: Sum of squares and mean squares are rounded figures

Table 2: Empirical results of the Gini indices

\begin{tabular}{llllll}
\hline Governorate & 1997 & & 2002 & & Changes in inequality \\
& No. of households & Gini index & No. of households & Gini index & \\
\hline Amman & 1,858 & 36.783 & 3,548 & 44.037 & + \\
Balqa & 288 & 35.664 & 891 & 43.221 & + \\
Zarka & 672 & 31.740 & 1,406 & 32.840 & + \\
Madaba & 288 & 35.901 & 369 & 36.981 & + \\
Irbid & 860 & 32.323 & 2,053 & 37.511 & + \\
Mafraq & 288 & 31.537 & 614 & 36.498 & + \\
Jerash & 285 & 33.533 & 354 & 33.910 & + \\
Ajloun & 284 & 29.895 & 268 & 38.019 & + \\
Karak & 288 & 28.235 & 629 & 40.553 & + \\
Tafeelah & 287 & 30.848 & 286 & 36.102 & - \\
Ma'an & 285 & 37.423 & 393 & 39.277 & + \\
Aqaba & 288 & 32.771 & 342 & 39.603 & + \\
Jordan & 5,971 & 33.880 & 11,153 &
\end{tabular}

Note: + means inequality had increased - means inequality had decreased

Table 3: Empirical results of the Atkinson's indices

\begin{tabular}{llllll}
\hline Governorate & 1997 & & 2002 & & Changes in inequality \\
& No. of house holds & Atkinson's index & No. of households & Atkinson's index & \\
\hline Amman & 1,858 & 44.390 & 3,548 & 48.971 & + \\
Balqa & 288 & 44.296 & 891 & 44.891 & + \\
Zarka & 672 & 32.836 & 1,406 & 32.978 & + \\
Madaba & 288 & 38.577 & 369 & 38.918 & + \\
Irbid & 860 & 35.587 & 2,053 & 38.274 & + \\
Mafraq & 288 & 32.042 & 614 & 36.888 & + \\
Jerash & 285 & 41.074 & 354 & 32.074 & - \\
Ajloun & 284 & 45.876 & 268 & 4.433 & + \\
Karak & 288 & 45.693 & 629 & 40.169 & + \\
Tafeelah & 287 & 47.303 & 286 & 36.145 & - \\
Ma'an & 285 & 41.596 & 393 & 40.379 & + \\
Aqaba & 288 & 32.334 & 342 & 41.490 & + \\
Jordan & 5,971 & 41.467 & 11,153 & & + \\
\hline
\end{tabular}

Table 4: Empirical results of the 90/10 ratio

\begin{tabular}{llllll}
\hline Governorate & 1997 & & 2002 & & Change in inequality \\
& No. of households & $90 / 10$ ratio & No. of households & $90 / 10$ ratio & \\
\hline Amman & 1,858 & 5.869 & 3,548 & 7.361 & + \\
Balqa & 288 & 6.708 & 891 & 7.038 & + \\
Zarka & 672 & 4.380 & 1,406 & 4.592 & + \\
Madaba & 288 & 5.266 & 369 & 5.456 & + \\
Irbid & 860 & 4.746 & 2,053 & 5.305 & + \\
Mafraq & 288 & 4.471 & 614 & 5.838 & + \\
Jerash & 285 & 5.351 & 354 & 4.539 & + \\
Ajloun & 284 & 4.948 & 268 & 6.295 & - \\
Karak & 288 & 3.843 & 629 & 5.129 & - \\
Tafeelah & 287 & 5.159 & 286 & 4.730 & - \\
Ma'an & 285 & 7.218 & 393 & 5.869 & + \\
Aqaba & 288 & 6.388 & 342 & 5.404 & + \\
Jordan & 5,971 & 5.193 & 11,153 & & + \\
\hline
\end{tabular}


Table 5: Empirical results of standard deviation of the natural log of real per capita income

\begin{tabular}{llllll}
\hline Governorate & 1997 & & 2002 & & Change in inequality \\
& $-\mathrm{No}$ of households & Standard deviation & No. of households & Standard deviation & \\
\hline Amman & 1,858 & .800 & 3,548 & 1.046 & + \\
Balqa & 288 & .763 & 891 & 1.088 & + \\
Zarka & 672 & .622 & 1,406 & .975 & + \\
Madaba & 288 & .668 & 369 & .972 & + \\
Irbid & 860 & .682 & 2,053 & 1.002 & + \\
Mafraq & 288 & .667 & 614 & .949 & + \\
Jerash & 285 & .749 & 354 & .985 & + \\
Ajloun & 284 & .582 & 268 & .968 & + \\
Karak & 288 & .742 & 629 & .992 & + \\
Tafeelah & 287 & .706 & 286 & 1.064 & + \\
Ma'an & 285 & .648 & 393 & 1.021 & + \\
Aqaba & 288 & .709 & 342 & 1.018 & + \\
Jordan & 5,971 & .736 & 11,153 & & + \\
\hline
\end{tabular}

Empirical results of the Atkinson's indices: As shown in Table 3, the Atkinson's indices provide empirical evidence that income inequality in Jordan has slightly increased from 41.467 to 41.490 . These results comply with those resulted from Gini indices for all governorates except for Jerash and Ajloun governorates. For these two governorates, the sample size was too small which may explain some of these variations, although the decrease in income inequality in Ajloun governorate was more obvious that that in Jerash governorate.

Empirical results of the $\mathbf{9 0 / 1 0}$ ratios: The 90/10 ratio, again, reveals a similar pattern, displaying a small increase in income inequality. As can be seen from Table 4 , the $90 / 10$ ratio had increased by nearly $4 \%$ between 1997 and 2002. While empirical evidence indicate that income inequality has increased by only $4 \%$ at the overall level of Jordan, higher inequalities can be noticed for large governorates such as the capital Amman, Balqa, Zarka and Irbid. It should be mentioned that the slight increase in the 90/10 ratio between 1997 and 2002 at the overall level could be attributed to the fact the $90 / 10$ ratio considers only the richest $10 \%$ and the poorest $10 \%$ of the population unlike the previous two indices that consider income of each individual household despite its rank in richness.

Empirical results of the standard deviation of the natural logarithm: Table 5 lists the 12 governorates of Jordan and their inequality index, as expressed by the standard deviation of the natural log of real per capita income. As can be seen, all values of the standard deviation of the natural logs displayed an increase in each governorate. These findings suggest that inequality has increased at the overall level and at governorates level.

In 1997, Amman, Balqa, and Jerash governorates found to be on the top of the list of all governorates that had greater inequality. On the other hand, Ma'an, Zarka, and Ajloun had the least inequality relative to other governorates. For 2002, Balqa, Ma'an, and Amman were the first three governorates that had higher inequality in relation to other governorates. Looking across the years, we find increases in income inequality over the period 1997-2002. This increase was approximately 38\%. Perhaps the most striking conclusion from Table 5 is that while inequality has increased within each governorate, the ranking of governorates has changed dramatically. Jerash, for example, ranked the third in 1997 and became the seventh in 2002, indicating that it gained a better position in relation to other governorates. On the other hand, both Ma'an and Karak were badly hit by inequality since Ma'an was the tenth in 1997 then became the second in 2002. This also applies to Karak governorate but to a lesser degree.

In sum, as Table 5 shows, Jordan has a serious problem of economic inequality.

\section{CONCLUSION}

This study has concentrated on analyzing economic inequality in real per capita household income in each governorate in Jordan, for both 1997 and 2002. The objective was to determine whether regional inequalities in income exist or not. Another objective was to see whether the status of economic inequality has improved or worsened, and if so, in which governorates. Looking at the empirical results, obtained from using four inequality measures, indicates that all measures did not give the same conclusion for each governorate. However, they all point to the conclusion that regional economic inequality is serious and increasing.

Therefore, one can conclude that poor people are concentrated in the some governorates and rich people are concentrated in the other. As a result, the commitment of Jordan to economic equality, and its 
ability to deliver it, has been severely eroded. The results of the tests, while revealing startling evidence concerning economic inequality in different geographical regions, indicate that economic and social policies had not paid off. It is fair to conclude therefore that the Jordanian economic and social policies had adopted in practice a relatively minimalist distributional objective, and failed to reduce the growing economic inequality, at least for the period 1997-2002. However, and as mentioned earlier, economic inequality is not caused by only economic policies but also by other external factors.

Effective implementation of economic policies concerning economic inequality reduction is more likely to succeed when there is regular monitoring, evaluation and revision of economic inequality strategy. While economic inequality figures may provide decision makers with a prima facie results that could be classified as intuitionism that will most likely cause confusion, statistical tests addressing economic inequality, as those demonstrated in this study, provide more concrete evidence than just looking at income figures and drawing vague conclusions. Income distribution must be settled and resettled continuously with some degree of success, or the economy will stagger from crisis to crisis. For this reason, sooner or later, the economy of Jordan has to adopt a norm, a code of behaviour which it will try to uphold, and which can be maintained with reasonable success. No one denies that many of the inequalities are probably indefensibly and economically unnecessary. But the theme of this study is that regional inequalities should be reduced, and that consensus ought to be possible as to the acceptable range and purpose of necessary inequalities. Unless this is possible, it is difficult to see where the struggle for the so-called "fair distribution of the development fruits" will lead, other than to a breakdown of the society by a process of escalation in conflicts.

In summary, Jordan's economic policies that aim at reducing regional inequality should better concentrate on improved regional spending controls, further tax reforms, and major structural or institutional changes in the budget process. The implementing of these policies is a challenging agenda that encompasses policies that will best encourage the goals of non-inflationary economic growth and efficient government spending that follow a more space-balanced approach. Finally, it should be emphasized that these policies are neither easy to implement nor guaranteed against slow growth or other economic woes. They are only the frameworks, which would maximize the opportunity to achieve inequality reduction. This agenda is a challenge not only for the present time, but also for many years to come.

\section{REFERENCES}

1. Assaf, G., 1979. The Size Distribution of Income in Jordan, Royal Scientific Society, Amman.

2. Saket, B., 1983. Varying sources of income in the Arab world as a balanced economic strategy. Royal Scientific Society, Amman. [in Arabic].

3. Abu, J.K., M. Buhbe and M. Smadi (Eds.), 1990. Income Distribution in Jordan, Friedrich Ebert Stiftung, Amman.

4. Kharabsheh, A., 2001. Factors affecting inequality of income distribution in Jordan. Dirasat: Administrative Sci., 28: 365-380.

5. Shaban, R.A., D. Abu-Gaida and A. Al-Naimat, 2001. Poverty Alleviation in Jordan: Lessons for the Future, World Bank, Washington D.C.

6. Barrett, G., T. Crossley and C. Worswick, 1999. Consumption and Income Inequality in Australia, Centre for Economic Policy Research, Australian National University, Discussion Paper No. 404.

7. Borland, J., 1998. Earnings Inequality in Australia: Changes, Causes and Consequences. Centre for Economic Policy Research Discussion Paper No. 390, Australia National University.

8. Harding, A., 1995. The impact of health, education and housing outlays upon income distribution in Australia in the 1990s. Aust. Econ. Rev., 281: 71-86.

9. Pendakur, K., 1998. Family income and consumption inequality in Canada over 1978-1992. Rev. Income and Wealth, 44: 259-283.

10. Harding, A., 1997. The suffering middle: Trends in income inequality in Australia 1982 to 1993-94. Aust. Econ. Rev., 304: 341-58.

11. Pendakur, K., 2001. Consumption poverty in Canada: 1969 to 1998. Canadian Public Policy, Jun., pp: 1-35.

12. Zaidi, A. and K. de Vos, 2001. Trends in consumption-based poverty and inequality in the European Union during the 1980s. J. Popul. Econ., 14: 367-390.

13. Costa, M. and C. Michelini, 1999. An analysis of the distribution of income and wealth among Italian households. Department of Applied and International Economics Discussion Paper, No. 99.11, Massey University, Aug.

14. Maltagliati, M. and C. Michelini, 1999. Equivalence scales and consumption inequality: A study of household consumption patterns in Italy. Department of Applied and International Economics Discussion Papers, No. 99.04, Massey University, May.

15. Blundell, R. and I. Preston, 1996. Income, expenditure and the livings standards of UK Households. Fiscal Studies, 16: 40-54. 
16. Blundell, R. and I. Preston, 1998. Consumption inequality and income uncertainty. Quart. J. Econ., May: 603-640.

17. Cutler, D. and L. Katz, 1992. Rising inequality? Am. Econ. Rev., 822: 546-551.

18. Slesnick, D., 1998. Empirical approaches to the measurement of welfare. J. Econ. Literature, 36: 2108-2165.

19. Slesnick, D., 2001. Consumption and Social Welfare. Harvard University Press.

20. Barro, R.J., 2000. Inequality and growth in a panel of countries. J. Economic Growth, 5: 5-32.

21. Milanovic, B., 2005. World Apart: Global and International Inequality 1950-2000. Princeton University Press, Princeton.
22. Behrman, J., N. Birdsall and M. Szekely, 2003. Economic policy and wage differentials in Latin America. Center for Global Development Working Paper No. 29, Washington DC.

23. Bardhan, P., 2005. Globalization, inequality and poverty: An Overview. University of California at Berkeley.

24. Alesina, A., R. Tella and R. McCulloch, 2004. Inequality and happiness: Are Americans and Europeans Different? J. Public Econ., 88: 20092042.

25. Gini, C., 1912. Variabilità e mutabilità. Reprinted in: Pizetti, E. and Salvemini, T. (Ed.). 1955. Memorie di metodologica statistica: Libreria Eredi Virgilio Veschi, Rome. 